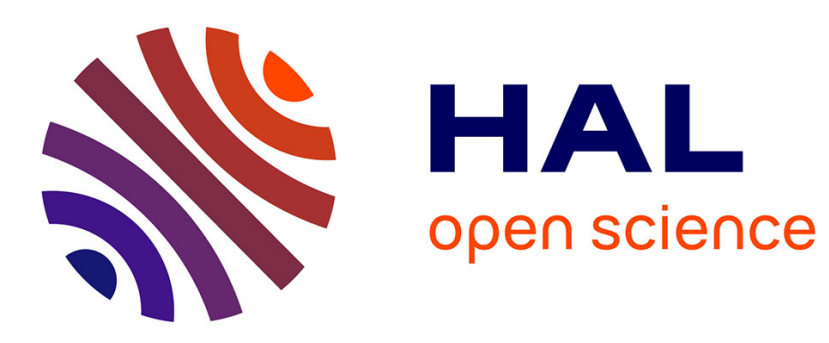

\title{
Towards green networking: Gossip based balanced battery usage routing protocol to minimize energy consumption of MANETs
}

Esubalew Yitayal, Jean-Marc Pierson, Dejene Ejigu

\section{- To cite this version:}

Esubalew Yitayal, Jean-Marc Pierson, Dejene Ejigu. Towards green networking: Gossip based balanced battery usage routing protocol to minimize energy consumption of MANETs. 12th edition of IEEE AFRICON 2015: Green Innovation for African Renaissance (AFRICON 2015), Sep 2015, Addis Abeba, Ethiopia. pp. 1-6. hal-01523664

\section{HAL Id: hal-01523664 \\ https://hal.science/hal-01523664}

Submitted on 16 May 2017

HAL is a multi-disciplinary open access archive for the deposit and dissemination of scientific research documents, whether they are published or not. The documents may come from teaching and research institutions in France or abroad, or from public or private research centers.
L'archive ouverte pluridisciplinaire HAL, est destinée au dépôt et à la diffusion de documents scientifiques de niveau recherche, publiés ou non, émanant des établissements d'enseignement et de recherche français ou étrangers, des laboratoires publics ou privés. 


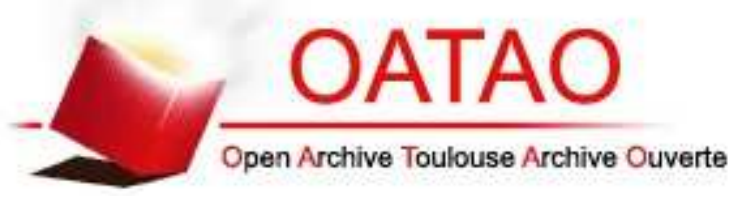

\section{Open Archive TOULOUSE Archive Ouverte (OATAO)}

OATAO is an open access repository that collects the work of Toulouse researchers and makes it freely available over the web where possible.

This is an author-deposited version published in : http://oatao.univ-toulouse.fr/ Eprints ID : 16997

The contribution was presented at AFRICON 2015 : http://sites.ieee.org/africon2015/

To cite this version : Yitayal, Esubalew and Pierson, Jean-Marc and Ejigu, Dejene Towards green networking: Gossip based balanced battery usage routing protocol to minimize energy consumption of MANETs. (2015) In: 12th edition of IEEE AFRICON 2015 : Green Innovation for African Renaissance (AFRICON 2015), 14 September 2015 - 17 September 2015 (Addis Abeba, Ethiopia).

Any correspondence concerning this service should be sent to the repository administrator: staff-oatao@listes-diff.inp-toulouse.fr 


\title{
Towards Green Networking: Gossip based Balanced Battery Usage Routing Protocol to Minimize Energy Consumption of MANETs
}

\author{
Esubalew Yitayal, Jean-Marc Pierson ${ }^{2}$, Dejene Ejigu ${ }^{1}$ \\ ${ }^{1}$ IT Doctoral Program, Addis Ababa University, \\ Addis Ababa, Ethiopia \\ ${ }^{2}$ Laboratoire IRIT UMR 5505, University of Toulouse 3 Paul Sabatier, \\ Toulouse, France
}

\begin{abstract}
Energy conservation is a critical issue in battery powered mobile nodes of mobile ad hoc networks (MANETs). Most MANETs routing protocols use some form of flooding to discover routes among mobile nodes. Despite various optimizations, many route discovery messages are still propagated without considering a coalesce effect of node density and residual energy. During route discovery process, each node of MANET should not blindly broadcast because malfunction of node or link might occur and allows establishing a new path from source to destination which creates extra energy consumption of nodes, sparse network density and a more likelihood occurrence of network partition. In this paper we are developing and evaluating an energy aware routing protocol called a gossip based balanced battery usage routing protocol (GBBU) which integrates minimum residual energy and node degree as cost metric to minimize and distribute energy consumption of MANETs based on Ad hoc on demand distance vector (AODV). The performance of the protocol is measured based on reachability, energy consumed per packet delivered, delivery ratio, average end-to-end delay, and network lifetime using network simulator-2.35. The simulation results show that GBBU routing protocol minimizes energy consumption per packet and fairly distribute energy usage across mobile nodes.
\end{abstract}

Keywords-GBBU-AODV; energy consumed per packet delivered; gossiping;reachability

\section{INTRODUCTION}

Energy efficiency is an important issue in battery-operated wireless devices that are used in wireless networks. Mobile Ad hoc Network (MANET) is a special type of wireless network in which a collection of independent mobile nodes form a temporary network without the aid of any pre-established infrastructure or centralized administration [1-3]. In wired networks the assumption is that nodes connected to the network have an unlimited amount of energy, hence energy efficiency is not a concern in protocol design. Unlike wired networks, mobile nodes in mobile ad hoc networks are typically powered by energy limited devices, usually batteries. Besides, the flooding nature of route discovery process in MANET routing protocols, the nature of a host being a router beyond application hosts, and the transmission and reception of information all consume energy. Though the problem is significant still most of the MANET routing protocols established routes based on minimum cost metrics usually minimum hop count and flooding of routing packets [4-6]. This may lead to a serious problem, often referred to as the "broadcast storm problem" [7], which creates a large number of redundant rebroadcast packets, energy consumption, collision and network bandwidth contention.

In recent years, many researchers have focused on the optimization of energy consumption of mobile nodes, from different points of view. Some of the proposed solutions try to adjust the transmission power of wireless nodes; other proposals tend to efficiently manage a sleep state for the nodes [8]. Finally, there are many proposals which try to reduce the number of routing overheads by means of probabilistic approach [7] [9-13]. However, routing protocols which do not consider energy as a cost metric tend to use nodes which have small residual battery capacity on the route which results in frequent broken links. Failure of node or link allows re-routing and establishing a new path from source to destination which creates extra energy consumption of nodes, sparse network connectivity and a more likelihood occurrences of network partition. Hence, energy aware routing protocols that consider battery capacity of an individual node during route establishment should be designed.

In this paper a new gossip based energy efficient protocol called GBBU-AODV, which uses residual energy and number of neighbors as a cost metric, is proposed. The proposed GBBU-AODV routing protocol minimizes energy consumption of MANET by avoiding routing of packets through nodes with low residual energy and reducing routing overhead.

The rest of the paper is organized as follows. In section II, an overview of MANET routing protocols is presented. We examine some of the proposed energy aware routing protocols for MANETs in section III. Section IV discusses our proposed work. In section V, performance analyses are made between GBBU-AODV and other protocols via Network simulator NS2.35 over a variety of network scenarios and performance metrics, and finally, Section VI concludes the paper. 


\section{MANET Routing PROTOCOLS}

In wireless ad-hoc networks, nodes are not only sources or destinations hosts, but also serve as routers to forward messages for other nodes that are not within direct wireless transmission range of each other. This characteristic of ad hoc network has led to the development of MANET specific routing protocols. MANET routing protocols could be broadly classified into two major categories based on the mechanisms of route discovery and routing information update employed: proactive (table-driven) and reactive (on-demand) [14].

Proactive routing protocols require each node to other nodes in the network exchange routing information periodically regardless of using the routes or not. Proactive protocols have the disadvantage of introducing more number of control packets due to periodical updates of stale route entries which results quick exhaustion of node's battery [15, 16]. Protocols of this type include Destination Sequenced Distance Vector (DSDV) [5] and Optimized Link State Routing (OLSR) [17]. On the other hand, reactive routing protocols do not exchange routing information periodically. Instead, they discover a route only when a source node requires a route to a destination. Typical and well-known examples of reactive routing protocols are Dynamic Source Routing (DSR) [4], Ad hoc On-demand Distance Vector (AODV) [6]. Proactive protocols inherently consume more energy than the Reactive ones; hence most of the research works involve modifications to reactive protocols. From the reactive routing protocols, most research works reveal that AODV is energy efficient protocols $[1,14,18]$.

Ad hoc On-demand Distance Vector (AODV): When a source node wishes to send data, but does not have valid route information to the destination, it initiates a route discovery process. Path discovery process is initiated by broadcasting a route request packet (RREQ) packet to its neighbors. When a node receives RREQ in case it has routing information to the destination, it sends a route reply (RREP) packet back to the source node. Otherwise, it rebroadcasts RREQ packet further to its neighbors till either the destination is reached or another node is found with a fresh enough route to the destination. In AODV, the routing process will not consider energy of each node as a cost metric rather it uses a minimum hop-count along the paths [6]. Hence less energy capable nodes might be part of an established route which results frequent broken link and hence consumes an additional energy.

In [1], we proposed a modified version of AODV called BBU-AODV routing protocol for MANETs. The BBUAODV routing protocol modifies route request packet by adding two additional fields called Minimum Residual Energy and Sum Residual Energy which keeps the minimum remaining energy and the sum of remaining energy along the path between source and destination respectively. Then the BBU-AODV algorithm integrates Minimum Residual Energy, Sum Residual Energy, Energy Threshold and hop count as a cost metrics to maximize network life time and distribute load among mobile nodes.

In BBU-AODV, when all nodes in some possible routes between a source-destination pair have large minimum residual energy than the energy threshold then a route with maximum of the difference of average sum of residual energy and energy threshold among the routes is selected for data transmission. Otherwise the maximum difference of the average minimum residual energy and energy threshold among the routes is selected.

The proposed BBU AODV protocol reported in [1] maximizes life time of $\bar{M}$ ANET and distributes load across mobile nodes within a network in a reasonable way than the prior related works. However the route discovery process of BBU-AODV still uses flooding to search a route between source and destination. For example, if the intermediate node does not have a valid route to destination, and $\mathrm{N}$ is the total number of nodes in the network, the number of possible broadcasts of an RREQ packet in AODV and BBU AODV is $\mathrm{N}-2$. These methods of route discovery can seriously affect the performance of the routing protocol in terms of communication overhead, end-to-end delay and energy consumption the so called broadcast storm problem $[1,2,7]$.

Hence this paper proposes a gossip based energy aware routing protocol called GBBU-AODV which minimizes energy consumption of BBU-AODV. To conduct the performance analysis of the GBBU routing protocols, we are implemented our gossip based energy aware routing protocol on balanced battery usage routing BBU-AODV.

\section{RELATED WORKS}

Recently, energy efficient routing in mobile ad hoc network has been addressed by some research works. The majority of energy efficient routing protocols for MANET try to reduce energy consumption by means of reducing number of rebroadcasting routing packets regardless of node's energy level. Each and every protocol has some advantages and shortcomings. None of them can perform better in every condition. It depends upon the network parameters which decide the protocol to be used. This section reviews some of the proposed energy efficient schemes based on AODV.

The probabilistic scheme [2, 7] is one of the approaches that aim at reducing routing packet redundancy. In this scheme, when a node receives a broadcast message for the first time, it rebroadcasts the message with fixed and predetermined probability $\mathrm{p}$ regardless of node's energy level and neighbor information. The researchers have shown that, the optimal value of $\mathrm{p}$ in terms of high reachability and saved rebroadcast is approximately equal to 0.07 . The approach reduces overheads but might suffer from frequent broken link and energy consumption due to negligence of the impact of node degree or number of neighbors and energy level of each node. Moreover the assignment of the probability is fixed irrespective of network conditions.

In GOSSIP approach [9], if a node with $\mathrm{n}$ neighbors receives a message and does not broadcast it, but then does not receive the message from at least $m=p * n$ neighbors within a reasonable timeout period, it broadcasts the message to all its neighbors with probability 1 . The optimal gossip probability of the scheme is 0.65 . The scheme has good performance in reachability and reduction of message overhead as compared to other flooding protocols. However the scheme did not consider energy metric during route discovery process. 
References $[19,20]$ have proposed fixed pair of probabilistic broadcast scheme where the forwarding probability $p$ is adjusted based on "Node degree information". Node degree is obtained by periodical exchange of "HELLO" packets between neighbors. Since node energy level is not considered in both approaches, energy consumption might occur due to frequent broken link.

The work on [19] proposes an adaptive probability value based on average number of neighbors. On receiving the first broadcast at a node, if the node degree of node is smaller than average number of node of the network the node rebroadcast a message with high probability otherwise it rebroadcasts with small probability. The objective of the approach is reducing the number of routing overhead rather than proposing energy efficient routing protocols. The approach has two shortcomings. The first one is small capacity of node's battery might be part of a route during route discovery. The second one is reachability i.e. the assignment of forwarding probability for rebroadcasting might not deliver the required percentage of a RREQ messages.

In the counter-based scheme, every node has a counter $\mathrm{C}$ to store a number of received packets. The node will rebroadcast the packet when $\mathrm{C}$ has a value less than predefined threshold within a period of Random Assessment Delay (RAD) time [7]. A recent approach which combines the advantages of using counter and probabilistic scheme has been proposed to solve the BSP in MANETs based on realistic mobility model [21].

The work on [22] proposes an adaptive probability value based on the number of neighbors. The proposed algorithm dynamically calculates the value of rebroadcast probability $p$ and assigns higher value of $p$ for sparse region and smaller value for dense region. However, this scheme did not consider the energy level of the intermediate nodes.

Research work on [23] proposes an AODV-EXT-BP protocol that reduces routing overheads by tuning probability with respect to the neighbor density and the posterior probability. The protocol depends on local topology information regardless of node's residual energy.

Reference [24] proposes a new adaptive probabilistic scheme (ABS) based on the ratio of the Number of neighbors for 1-hope and the Number of neighbors within node's transmission range to alleviate the problem of broadcast storm problem. The approach did not have notion of energy related metrics.

\section{THE PROPOSED SOLUTION}

The objective of this work is to propose an energy efficient routing protocol called GBBU-AODV for MANETS. The algorithm combines minimum remaining energy and node density or number of neighbor nodes as a cost metric to minimize energy consumption of MANETs. The GBBUAODV routing protocol overcomes shortcoming of BBU AODV [1] and traditional routing protocols of MANET while still maintaining an acceptable level of reachability. In GBBU_AODV scheme, the gossiping probability for each node is calculated based on the minimum residual energy from source to the node itself. Thus the algorithm protects small residual energy nodes as part of data communication route by assigning small rebroadcasting probabilities for each intermediate node on the path. For example S-A-B-C-D is a route between source $\mathrm{S}$ and destination $\mathrm{D}$. Node $\mathrm{A}$ has a smallest residual energy. Then node $\mathrm{B}$ and node $\mathrm{C}$ rebroadcast the packet with a probability related to node $\mathrm{A}$ residual energy. Hence the probability of Path S-A-B-C-D reaching to destination node $\mathrm{D}$ is small as each intermediate node rebroadcast with a probability related to the smaller residual energy of node A. Moreover beyond protecting critical nodes as part of the route, the algorithm also minimizes the transmission power required during rebroadcasting of packets.

The algorithm of GBBU-AODV is depicted in Fig.1. When a node $\mathrm{Y}$ with $\mathrm{n}$ neighbors receives a broadcast packet for the first time, the node forwards the packet with a gossiping probability $\mathrm{P}_{\mathrm{y}}$. If a node fails to rebroadcast a packet, it sets a timer and waits a copy of the number of received RREQ i.e. $\mathrm{C}$ from its neighbor nodes. If a node does not receive $\mathrm{c}=\mathrm{n}^{*} \mathrm{P}_{\mathrm{th}} ; \mathrm{P}_{\text {th }}$ is the gossiping probability threshold, number of RREQ packets within a gossiping timeout period, it rebroadcasts the packet otherwise it drops. More importantly, the new gossip based energy efficient scheme:-

a) adjusts the gossiping probability based on the global and local neighborhood information such as minimum residual energy and neighbor density level.

b) sets the value of gossiping probability during the run time rather than during the design time to make it more reactive to operating conditions,

c) does not require an additional hardware to operate it for example GPS.

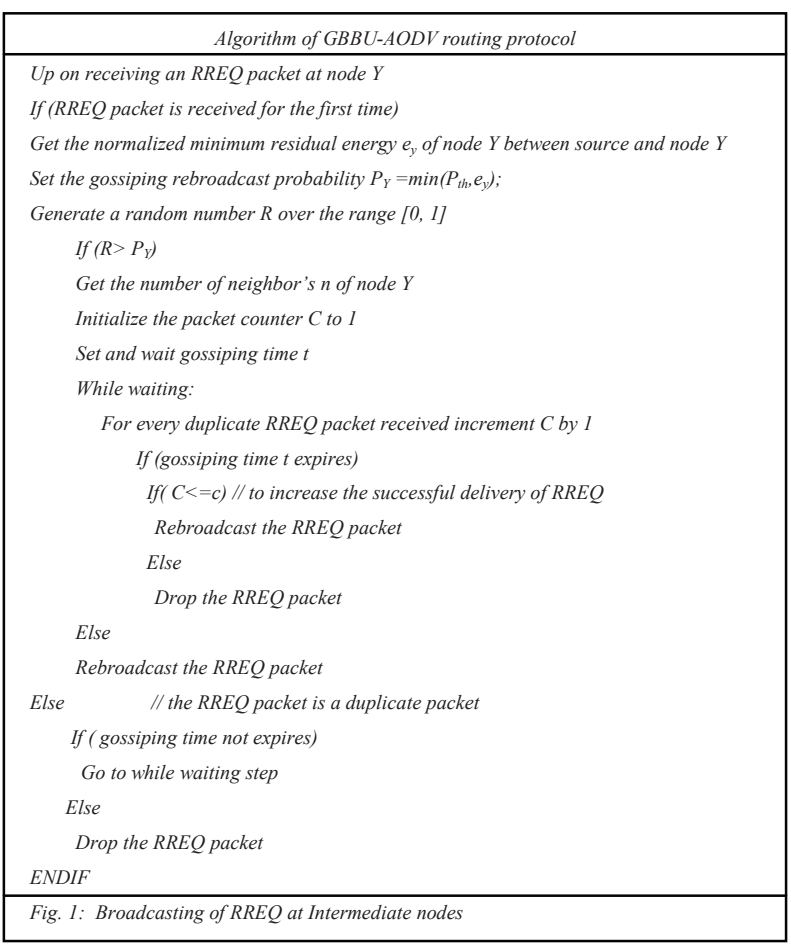




\section{Simulation AND Results}

\section{A. Simulation Environment}

In this paper the simulation analysis is carried out using Network Simulators-2 version 2.35 [25] on laptop equipped with 2.6GHz (Intel Q9400 Core i5) processor,4 GB of RAM and Ubuntu Linux version 10.04. The performance of the proposed energy efficient routing protocol is evaluated against AODV [6], and Gossip based [9] routing protocols. The physical radio frequency characteristics of each wireless transceiver are chosen to mimic the commercial Lucent WLAN technology [26] with a nominal bit rate of $2 \mathrm{Mbps}$ and a transmission range of 250 meters. The initial energy of each node was randomly set between 60 to 200 Joule with transmission and reception power of $0.28 \mathrm{~W}$ and $0.18 \mathrm{~W}$ respectively [27].

The simulation setup consists of an area of $1000 \mathrm{~m} \mathrm{X}$ $1000 \mathrm{~m}$ with different number of nodes from 80 to 150 for each simulation. Each packet starts travelling from a random location to a random destination with a randomly chosen speed between 0 and $20 \mathrm{~m} / \mathrm{sec}$. When a node reaches a destination, it moves to another randomly chosen destination after a pause time of $20 \mathrm{sec}$. Constant Bit Rate (CBR) traffic source of 5 packets/sec with packet size of 512 bytes is used.

Each data point represents an average of 30 numbers of runs of simulations. The timeout period of GBBU_AODV gossiping is $5 *$ NODE TRAVERSAL TIME as reported in [3, 9]. The NODE TRAVERSAL TIME parameter of AODV is a base point for our Gossip timeout period [3]. The threshold value for the counter is $1[9]$.

All the simulations were run for a period of $1000 \mathrm{sec}$. Once the trace file is generated from the simulation, a Perl and AWK scripts are used to analyze the information from the trace files. The parameters used in the simulation are summarized in Table 1.

TABle 1. Simulation Parameters

\begin{tabular}{|l|l|}
\hline \multicolumn{1}{|c|}{ Simulation Parameters } & \multicolumn{1}{c|}{ Value } \\
\hline Simulator & NS-2 (v.3.35) \\
\hline Transmitter range & 250 meters \\
\hline Bandwidth & 2 Mbps \\
\hline Interface queue length & 50 Packets \\
\hline Traffic type & CBR \\
\hline Traffic Source & 9 \\
\hline Packet size & 512 bytes \\
\hline Simulation time & 1000 sec \\
\hline Number of trials & 30 \\
\hline Geographical areas & $1000 \mathrm{~m}$ x $1000 \mathrm{~m}$ \\
\hline Number of nodes & $80,100,110, \ldots, 150$ \\
\hline Mobility Model & Random way point \\
\hline Maximum speed & $20 \mathrm{~m} / \mathrm{s}$ \\
\hline Number of received RREQ (c) & 2 \\
\hline Pause time & $20 \mathrm{sec}$ \\
\hline Initial Energy & $60-210$ Joule \\
\hline Transmission Power & 0.28 watt \\
\hline Reception Power & 0.18 watt \\
\hline
\end{tabular}


collision and channel contention which makes some of the communication channel free for the transmission of actual data packets.

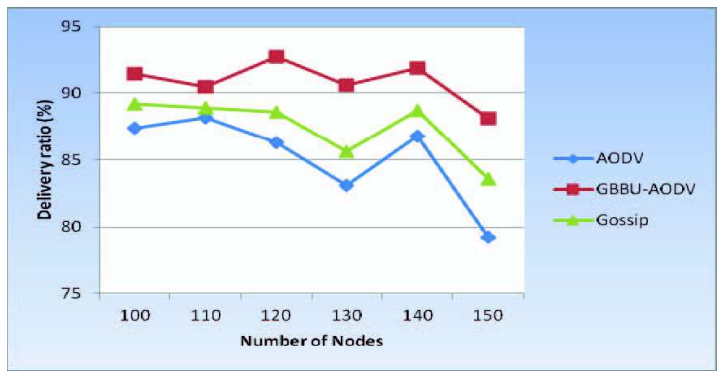

Fig.3. Delivery ratio with different number of nodes

\section{3) Energy consumed per Packet Delivered}

The energy consumption per packet reduces in GBBUAODV than both AODV and gossip routing protocols as shown in Fig.4. This is because energy capable nodes are part of an established route during route discovery so that the route can be used for extended period of time for data packets transmission.

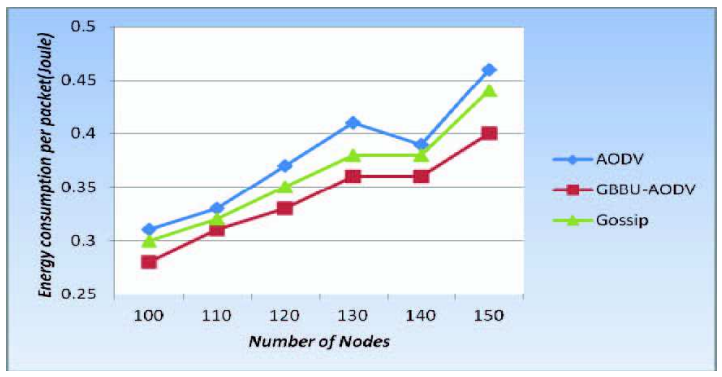

Fig.4. Energy consumed per packet delivered with different number of nodes

\section{4) Average End-to-End Delay}

The average end to end delay in AODV is larger than both GBBU-AODV and gossip as shown in Fig.5. This is because in AODV most of the RREQ messages fail to reach their destinations due to high probability of packet collisions, channel contention and queue delay caused by excessive redundant retransmissions and flooding. Thus the amount of time required for the packets to be transmitted between source and destination is increased.

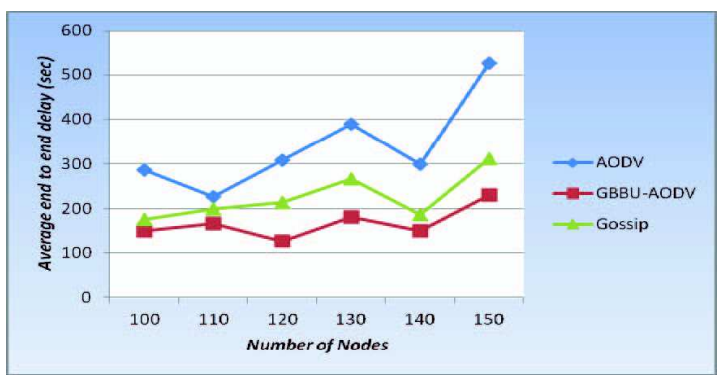

Fig.5. Average end to end delay with different number of nodes

\section{5) Network Life time}

Our modified gossip based energy aware algorithm outperforms both AODV and gossip routing protocols in terms of network life time as illustrated by Fig. 6. The improvement gained by GBBU seems insignificant but GBBU delivered an average of 3,120 and 2,150 more data packets than both AODV and gossip routing respectively. Under these circumstances there is still a lifetime improvements in GBBU. This is because the GBBU routing protocol selects an energy efficient nodes for data transmission which secures the nodes from early die due to their energy draw off.

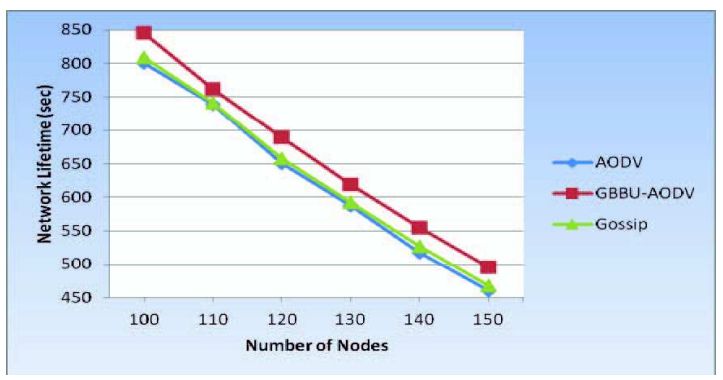

Fig.6. Network lifetime with different number of nodes

\section{CONCLUSION}

Energy efficiency is an important issue for batterypowered mobile nodes in a MANET. The existing routing protocols suffer from excessive flooding and frequent broken link due to the nature of route discovery process. Reducing number of flooding packets could be one solution for energy efficiency. However routing protocols which do not consider energy as a cost metric tend to use nodes which have small residual battery capacity on the route which results frequent broken link. Failure of node or link allows re-routing and establishing a new path from source to destination which creates extra energy consumptions, sparse network connectivity and a more likelihood occurrences of network partition. Hence, to overcome these problems, a GBBUAODV routing protocol that considers battery capacity and node degree of an individual node during route establishment is designed. The simulation results show that GBBU-AODV has better energy consumption per packet delivered, delivery ratio, average end-to-end delay and network lifetime than both AODV and gossip routing protocols. This paper considers the impact of number of nodes on the performance of GBBUAODV routing protocols on several metrics. The impact of traffic sources, mobility and pause time on the performance of GBBU-AODV are among our future works.

\section{REFERENCES}

[1] E. Yitayal, J.M. Pierson, and D. Ejigu, "A Balanced Battery Usage Routing Protocol to Maximize Network Lifetime of MANET Based on AODV," S. Balandin et al. (Eds.): NEW2AN/ruSMART 2014, LNCS 8638, pp.266-279, 2014.

[2] C. S. R. Murphy and B. S. Manoj, "Ad Hoc Wireless Networks: Architectures and Protocols". New Jersey: Prentice Hall PTR, May 24, 2004

[3] J. Hoebeke, I. Moerman, B. Dhoedt, and P. Demeester, "An Overview of Mobile Ad Hoc Networks: Applications and Challenges," 43rd European Telecommunications Congress, Journal of the Communications Network, Vol. 3, pp. 60-66, July 2004. 
[4] D.Johnson, Y. Hu and D.Maltz, , "The dynamic source routing (DSR) protocol for mobile ad hoc network," IETF MANET Working Group, Internet Draft, RFC 4728, February 2007.

[5] C. Perkins and P. Bhagwat, "Highly dynamic destination sequenced distance-vector routing (DSDV) for mobile computers," Computer Communications Review, pp. 234-244, October 1994.

[6] C. Perkins, E. B. Royer, and S. Das, "Ad hoc on-demand distance vector (AODV) routing”, IETF MANET Working Group INTERNET DRAFT, RFC 3561, July 2003.

[7] Y. C. Tseng, S. Y. Ni, Y. S. Chen, and J. P. Sheu, "The broadcast storm problem in a mobile ad hoc network," Wireless Networks 8, pp. 153$167,2002$.

[8] S. Prakash, J.P. Saini, S.C. Gupta, and S.Vijay, " Design and Implementation of Variable Range Energy Aware Dynamic Source Routing Protocol for Mobile Ad Hoc Networks," International Journal of Computer Engineering and Technology (IJCET), pp. 105-123 , 2013.

[9] Z. J.Haas, J. Y.Halper, and L. Li, “ Gossip Based Ad Hoc Routing, " IEEE Transactions on networking, Vol.14, No.3, June 2006.

[10] Y.Sasson, D.Cavin and A.Schiper, "Probabilistic Broadcast for Flooding in Wireless Mobile Ad hoc Networks," Swiss Federal Institute of Technology (EPFL), Technical Report IC/2002/54, 2002.

[11] A.khelil and N.suri,"Gossiping: Adaptive and Reliable Broadcasting in MANETs", Lecture Notes in Computer Science Volume 4746, pp 123$141,2007$.

[12] S.M.Senouci and M.Naimi, "New routing for Balanced Energy Consumption in Mobile Adhoc Networks", PE-WASUN'05, montreal, quebec, Canada, October 2005.

[13] C. E.Jones, K. M.Sivalingam, , P.Agrawal, and J. C. Chen, "A survey of energy efficient network protocols for wireless networks", Wireless networks, 2001.

[14] G.Vijaya Kumar, Y.Vasudeva Reddyr and Dr.M.Nagendra,"Current Research Work on Routing Protocols for MANET: A Literature Survey", (IJCSE) International Journal on Computer Science and Engineering, 2010.

[15] J. Broch, D.A.Maltz,Y.-C. Hu, D.B.Johnson, and J. Jetcheva, "A performance comparison of multi-hop wireless ad-hoc network routing protocols," Proceedings of ACM/IEEE International Conference on Mobile Computing and Networking (MOBICOM'98), pp. 85-97, October 1998.

[16] H. Jiang and J. J. G-L-Aceves, "Performance comparison of three routing protocols for ad hoc networks," Proceedings of 10th International Conference on Computer Communications and Networks, pp. 547-554, 2001.

[17] P.Jacquet, P.M.hlethaler, T.Clausen, A.Laouiti, A.Qayyum, L.Viennot, "Optimized Link State Routing Protocol for Ad Hoc Networks".IEEE INMIC , pp 62-68, 2001.

[18] A.P. Patil, K.R.Kanth, B.Sharanya, M.P.D.Kumar, and J.Malavika, "Design of an Energy Efficient Routing Protocol for MANETs based on AODV" International Journal of Computer Science IJCSI, pp. 215-220, 2011.

[19] M.B. Yassein, M.O. Khaoua, L.M. Mackenzie, S. Papanastasiou, and A. Jamal "Improving route discovery in on-demand routing protocols using local topology information in MANETs," Proceedings of the ACM international workshop on Performance monitoring, measurement, and evaluation of heterogeneous wireless and wired networks, pp. 9599, October 2006.

[20] M.B. Yassein, M.O. Khaoua, L.M. Mackenzie, and S. Papanastasiou, "Performance analysis of adjusted probabilistic broadcasting in mobile ad hoc networks," International Journal of Wireless Information Networks, Vol. 13, No. 2, pp.1-14, April 2006.

[21] M. Aminu, M. O. Khaoua, L.M. Mackenzie, and J. Abdulai, “ Performance evaluation of an efficient counter-based scheme for mobile ad hoc networks based on realistic mobility model, " International Syposium on Performance Evaluation of Computer and Telecommunication Systems SPECTS, pp. 16-18, June 2008

[22] A.M. Hanashi, I. Awan, and M. Woodward, "Improving Route Discovery of Dynamic Probabilistic Flooding in On-Demand Routing Protocols for MANETs,"16th Telecommunications forum TELFOR, pp. 89-92, November 2008.
[23] V. Kanakaris, D.L. Ndzi, K. Ovaliadis and Y. Yang, “ A new RREQ message forwarding technique based on Bayesian probability theory," EURASIP Journal on Wireless Communications and Networking, pp. 1-12, 2012.

[24] M.B. Khalaf, A.Y.A. Dubai and W. Buchanan, " A New Adaptive Broadcasting Approach for Mobile Ad hoc Networks," $6^{\text {th }}$ International Conference on Wireless Advanced (WiAD) IEEE, pp. 1-6, June 2010.

[25] Network Simulator, ns-2, http://www.isi.edu/nsnam/-ns/.

[26] A. Kamerman and L. Monteban, "WaveLAN II: A high-performance wireless LAN for unlicensed band," Bell Labs Technical Journal, vol. 2, pp. 118-133, 1997.

[27] L.M. Feeney, and M.Nilsson, "Investigating the Energy Consumption of a Wireless Network Interface in an Ad Hoc Networking Environment," Twentieth Annual Joint Conference of the IEEE Computer and Communications Socities, vol. 3, pp. 1548-1557, 2001. 